\title{
Construction of Patent Claims Using Axiomatic Design
}

\author{
Petru Dusa ${ }^{1 *}$,Eugen Purice ${ }^{1}$, Gheorghe Nagit $^{1}$, Oana Dodun ${ }^{1}$, Marius Ripanu ${ }^{1}$ and Laurentiu Slatineanu ${ }^{1}$ \\ ${ }^{1}$ Technical University Gheorghe Asachi of Iasi, Bvd. D. Mangeron, Nr. 39A, Iasi, Romania
}

\begin{abstract}
Patent claims play an important role in every patent case and it is the core for evaluation of infringement, validity or originality. There are two main types of claims: the independent claims (stand on their own), and the dependent claims (depending on a single/several claim/claims). Axiomatic design is a design theory that is based on the axioms. The axiomatic design theory makes use of corollaries and theorems which guide/help designers mapping functional domain to physical domain. The relation between functional requirements and design parameters is assured by so called design matrix. In an ideal design the number of design parameters is equal to the number of functional requirements, and the functional requirements are always kept independent from each other. When there are more design parameters than functional requirements, the design is a redundant design. A coupled design can became decoupled by selecting different set of design parameters. The idea of construction of patent claims using Axiomatic Design is based on the assumption of independent claims as a part of an ideal design and dependent claims as a part of a decoupled design.
\end{abstract}

\section{Introduction}

Elaboration of the claims is a challenge when preparing the patenting documentation. In a patent, the claims define extension, the scope of the protection for which the patent is conferred. The claims are intended to define what is protected by the patent.

The Five IP Office (IP5) is a forum of five intellectual property offices. The members of IP5 are: European Patent Office (EPO), Japan Patent Office (JPO), Korean Intellectual Property Office (KIPO), State Intellectual Property Office of the People's Republic of China (SIPO) and United States Patent and Trademark Office (USPTO). "The IP5 Offices account for $90 \%$ of all patent applications filed worldwide and for $93 \%$ of all work carried out under the Patent Cooperation Treaty (PCT).’[1]

In all jurisdictions [2-15], the patent serves to exclude others from producing, using, importing, selling or offering for sale what the subject matter defines in the claims.

In order to exclude someone from the use of a patented invention, the claims must include a set of limitations that differentiate the invention from what has been done prior to the invention.

The claims are used to decide the area of protection offered by the patent, but the way of use may vary from one jurisdiction to another.

There are inherent difficulties in using language to define the boundaries of the right of use, and jurisprudence is criticized for the lack of a theoretical and practical coherence of building claims.

Claims can be a matter of concern at least from two perspectives: building claims and interpreting claims.
Some theorists are working on structured framework for claims construction [16-18], others are more interested in ways of interpreting claims [19].

To reduce ambiguities in constructing and interpreting claims, consistent dictionaries of terms have been developed [20].

Patent Offices specialists use different tools to analyse claims, especially from the point of view of infringement of rights. Such an instrument is the claim chart.

A claim chart is a two-column table showing the main aspects of a patent claim in a column, and in the other column there are presented similarities with claims from other patents [21].

The purpose of this paper is to analyse and demonstrate the possibility of mapping concepts in the field of patents with the concepts of Axiomatic Design theory to develop an analytical tool useful in building / analysing patent claims.

\section{The main concepts in the field of patents}

\subsection{Type of claims}

Patents include multiple claims each of which represent a separate property right. Usually patents have independent claims and one or more dependent claims. Independent claims are written as standalone and dependent claims add some additional detail or limitation to that is claimed in the independent claim. There are possible for a dependent claim to depend from

\footnotetext{
* Corresponding author: pdusa@tcm.tuiasi.ro
} 
another dependent claim which depends from an independent claim.

According with Rule 6 [4] claims shall contain:

(1) a statement indicating those technical features of the invention which are necessary for the definition of the claimed subject matter but which, in combination, are part of the prior art,

(2) a characterizing portion - preceded by the words "characterized in that," "characterized by," "wherein the improvement comprises," or any other words to the same effect - stating concisely the technical features which, in combination with the features stated under (1), it is desired to protect.

\subsection{Disclosure of the invention}

Patent application shall disclose the invention in a manner sufficiently clear and complete for it to be carried out by a person skilled in the art, without any inventive step $[8,15]$.

\subsection{Unity of invention}

Patent application shall relate to one invention only or to a group of invention so linked as to form a single general inventive concept $[3,4,8,15]$.

\subsection{Novelty of invention}

An invention shall be considered to be new if it does not form part of the state of the art. The state of the art shall be held to comprise everything made available to the public by means of a written or oral description, by use, or in any other way, before the date of filing of the Patent Office patent application $[8,15]$.

\section{Axiomatic design theory (principles)}

Axiomatic design [22, 23] is a design theory and methodology based on the Independence Axiom and the Information Axiom. The methodology contains corollaries and theorems which guide/help designers mapping functional and physical domains (see Figure 1).

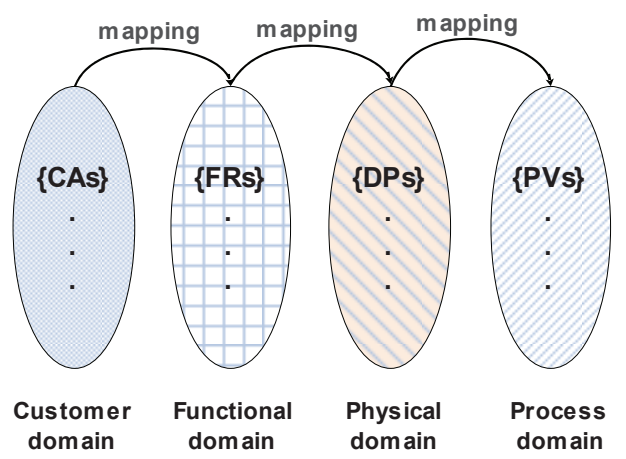

Fig. 1. Domains mapping [23, 24].

According with Axiomatic Design theory [22, 23] design involves a continuous interplay between what is wanted to achieve and how is wanted to achieve it. It must determine the design's objectives by defining it in terms of specific requirements called functional requirements (FRs). To satisfy functional requirements a physical embodiment characterized in terms of design parameters (DPs) must be created

The basic assumption of Axiomatic Design (AD) approach to design is that there exist two axioms that determine good design practice: FRs)

Axiom 1: The Independence Axiom (independence of

Axiom 2: The information Axiom (minimize the information content of the design)

Independence axiom may be mathematical expressed by the design equation (1):

$$
\{\boldsymbol{F R}\}=[A]\{\boldsymbol{D P}\}
$$

Where:

$\{F R\}$ is the functional requirement vector;

$\{D P\}$ is the design parameters vector;

$[A]$ is the design matrix.

In particular case equation (1) can be written in the form shown in equation (2)

$$
\left[\begin{array}{l}
F R_{1} \\
F R_{2} \\
F R_{3}
\end{array}\right]=\left[\begin{array}{ccc}
A_{11} & A_{12} & A_{13} \\
A_{21} & A_{22} & A_{23} \\
A_{31} & A_{32} & A_{33}
\end{array}\right] *\left[\begin{array}{c}
D P_{1} \\
D P_{2} \\
D P_{3}
\end{array}\right]
$$

If all of the elements of the design matrix are nonzero axiom 1 cannot be respected and the design is called coupled design.

In the case when only the diagonal elements from design matrix are different from zero (see equation 3 ) the design satisfies the Axiom 1 and is defined as an uncoupled design.

$$
\left[\begin{array}{l}
F R_{1} \\
F R_{2} \\
F R_{3}
\end{array}\right]=\left[\begin{array}{ccc}
A_{11} & 0 & 0 \\
0 & A_{22} & 0 \\
0 & 0 & A_{33}
\end{array}\right] *\left[\begin{array}{c}
D P_{1} \\
D P_{2} \\
D P_{3}
\end{array}\right]
$$

A coupled design can be decupled. A case is presented by equation (4) where the design matrix is a triangular matrix. The independence of FRs can be assured by adjusting the design parameters in a particular order (DP1 first, DP2 second and third DP3).

$$
\left[\begin{array}{l}
F R_{1} \\
F R_{2} \\
F R_{3}
\end{array}\right]=\left[\begin{array}{ccc}
A_{11} & 0 & 0 \\
A_{21} & A_{22} & 0 \\
A_{31} & A_{32} & A_{33}
\end{array}\right] *\left[\begin{array}{c}
D P_{1} \\
D P_{2} \\
D P_{3}
\end{array}\right]
$$

This system is called decoupled design.

It was presented these fundamental elements of $\mathrm{AD}$ theory to serve the approach of the possible use of the theory for patent analysis and specifically for the construction of claims. The theory make use of many theorems and corollaries and in-depth knowledge can be 
obtained from de books written by the founder of the theory [22,23].

\section{Mapping AD field concepts to the Patent field concepts}

The analysis of several concepts used in the field of patents (see chapter 2) and the fundamentals of $\mathrm{AD}$ theory (see chapter 3) led to the hypothesis that AD theory could be used to build patent claims and to analyse the solutions claimed in existing patents.

On the one hand, the patent field calls for concepts such as independent claims, dependent claims, invention disclosure, novelty of the invention, and on the other hand $\mathrm{AD}$ uses concepts such as the axiom of independence, the axiom of minimizing information, redundant solution.

It was aimed to analyse how the concepts in the two fields could be mapped in order to use the methodology and scientific tools of the AD theory to solve some controversial problems in the patent field, especially in the construction and analysis of claims.

Table 1 shows how was mapped the concepts of Axiomatic Design field to concepts in the field of patents, especially the construction and analysis of claims. It can be seen that it was mapped the axiom of the independence of the factors with the independence / dependence of the claims. If the system had an uncoupled design, the claims should all be independent. In other words, if the number of functional requirements is equal to the number of design parameters and the design matrix is diagonal, the solution claims should be all independent.

Table 1. Mapping the Axiomatic Design field concepts with patent field concepts (claim construction and analyses)

\begin{tabular}{|c|c|c|}
\hline \multicolumn{2}{|c|}{ Axiomatic Design Field } & Patent Field \\
\hline \multirow{2}{*}{$\begin{array}{l}\text { Axiom 1: The } \\
\text { Independence } \\
\text { Axiom } \\
\text { (independence } \\
\text { of FRs) }\end{array}$} & $\begin{array}{l}\text { Ideal design } \\
\text { (number of } \mathrm{FR}_{\mathrm{s}} \\
\text { equal to } \\
\text { number of } \mathrm{DP}_{\mathrm{s}} \\
\text { (uncoupled design) }\end{array}$ & $\begin{array}{l}\text { Independent } \\
\text { claims }\end{array}$ \\
\hline & decoupled design & $\begin{array}{l}\text { Dependent } \\
\text { claims }\end{array}$ \\
\hline \multicolumn{2}{|c|}{$\begin{array}{l}\text { Axiom 2: The information } \\
\text { Axiom ( minimize the information } \\
\text { content of the design) }\end{array}$} & $\begin{array}{l}\text { Disclosure of the } \\
\text { invention }\end{array}$ \\
\hline \multicolumn{2}{|c|}{$\begin{array}{l}\text { When the original set of FRs is } \\
\text { changed, a new solution must be } \\
\text { found. The new solution may not be } \\
\text { derived by simply modifying the } \\
\text { previously obtained solution that } \\
\text { was acceptable only for the original } \\
\text { set of FRs [23]. }\end{array}$} & $\begin{array}{l}\text { Novelty of } \\
\text { invention }\end{array}$ \\
\hline \multicolumn{2}{|c|}{ Minimum number of FRs. } & $\begin{array}{l}\text { Unity of } \\
\text { invention }\end{array}$ \\
\hline
\end{tabular}

If the design matrix is decoupled, then the solution also has dependent claims.

It was assumed that axiom 2 (minimizing the content of design information) from Axiomatic Design theory can be mapped with the rule contained in all patent jurisdictions relating to disclosure of the invention.

According with AD theory FRs are defined to be the minimum set of independent requirements that completely characterize the design objective for a specific need. Corresponding to a set of FRs there can be many design solutions. When the original set of FRs is changed, a new solution must be found. The new solution may not be derived by simply modifying the previously obtained solution that was acceptable only for the original set of FRs [22].

Some designers believe that if their products can perform more than specified, the products are better. The product is overdesigned. By consequence the product is more complex and less reliable than is necessary. A good designer must have the ability to choose a minimum number of FRs [22].

\section{Case study}

In the following, in accordance with the foregoing, an invention patent which has been granted by a patent office [24] will be subject to analysis. The patent relates to a flexible hose crimping machine. In the paper is presented the abstract of the patent, the relevant figures from the patent application (Figures 2-7) that allow the understanding of the solution and the claims.

The invention relates to an automatic crimping machine, used in particular for the assembly of flexible tubes, with or without insertion, on the nipples.

According to the invention's abstract, the automatic crimping machine is composed of a frame having a hydraulic block connected with an electronic equipment and a crimping head (A) assembled with a positioning block (B) and actuated by an oscillating hydraulic motor (2). The crimping head (A) consists of a stator (4) provided with some guides (5), in which they glide some gripping jaw (6), having assembled some crimping tools (7) around which are assembled the springs (8). The movement of the gripping jaw (6) resulting from the oscillating rotation, relative to the stator (4), on some bearings (9), of a rotor (10), which are joined with cams (11), in contact by some bearings (12) with some beams (13) which can slide on some ball guides (14) from the stator (4), turning the rotation movement of the rotor (10) into translation of the clamping dies (6). The positioning block (B) is constituted by a cylinder body (19) in which a piston (20) mounted in the middle of a tubular rod (21) having on its end a chuck collet (22) and a ruler on the other end with the limiter (23). Inside the tubular rod (21) there is moved a piston (24) mounted on a rod (25) carrying a conical element (26) which, together with the chuck collet (22), performs the gripping under the action of a fluid, which selected by a distributor (27), go through an orifice (j) into a cavity (k) in the cylinder (19), from where through an orifice (1) is introduced into a cavity $(\mathrm{m})$ of the rod (21),producing 
first the pretension by first moving the piston (24) and then positioning by further displacement of the piston (20) by the discharge of the fluid from a cavity (n) by means of an orifice (o) associated with a hydraulic resistance (28), compared to the discharge of the fluid from a cavity (p) through an orifice (r) without hydraulic resistance.

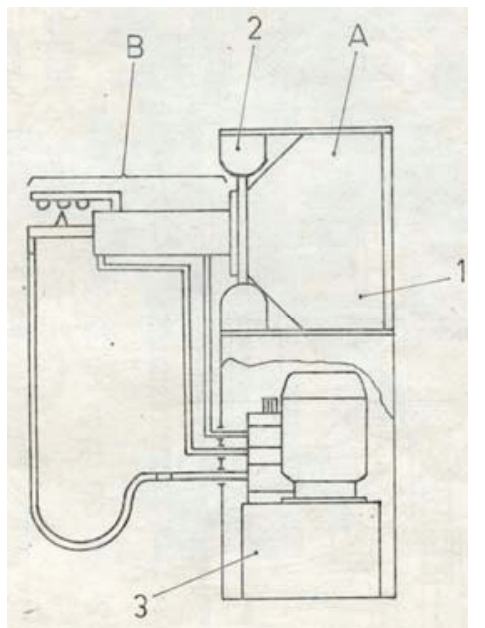

Fig. 2. Side view of the crimping machine [24].

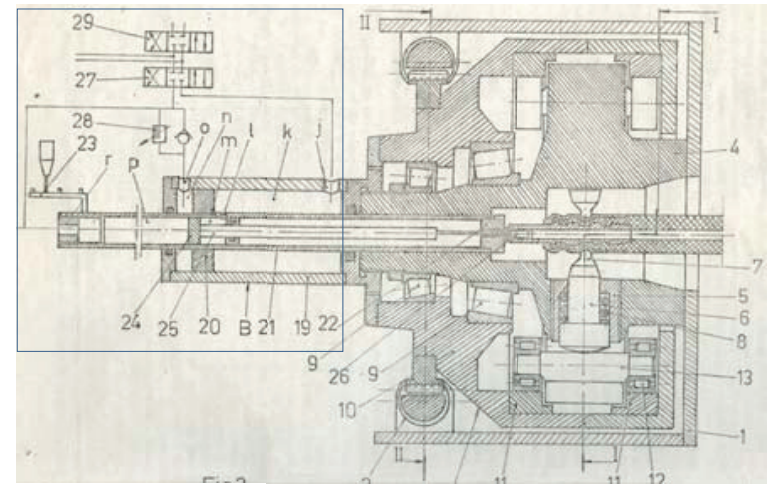

Fig. 3. Longitudinal section through crimp head and positioning cylinder [24].

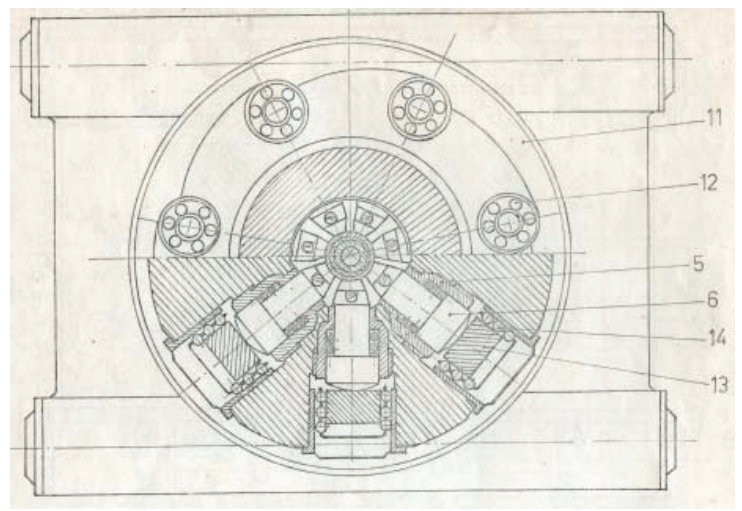

Fig. 4. Cross section through the crimping head [24].

The patent claims are presented below. In the text of each claim a reference was made to the figures containing elements specified in the text.

First claim (see Figures 2-5): An automatic crimping machine comprising a frame having in its interior a hydraulic block connected to an electronic equipment, characterized in that, in order to increase the productivity of the work, it includes a crimping head (A) assembled with a positioning block (B) and actuated by an oscillating hydraulic motor (2), the crimping head (A) consists of a stator (4) provided with some guides (5), in which they glide some gripping jaw (6), having assembled some crimping tools (7) around which are assembled the springs (8), the movement of the gripping jaw (6) resulting from the oscillating rotation, relative to the stator (4), on some bearings (9), of a rotor (10), which are joined with cams (11), in contact by some bearings (12) with some beams (13) which can slide on some ball guides (14) from the stator (4), turning the rotation movement of the rotor (10) into translation of the clamping dies (6).

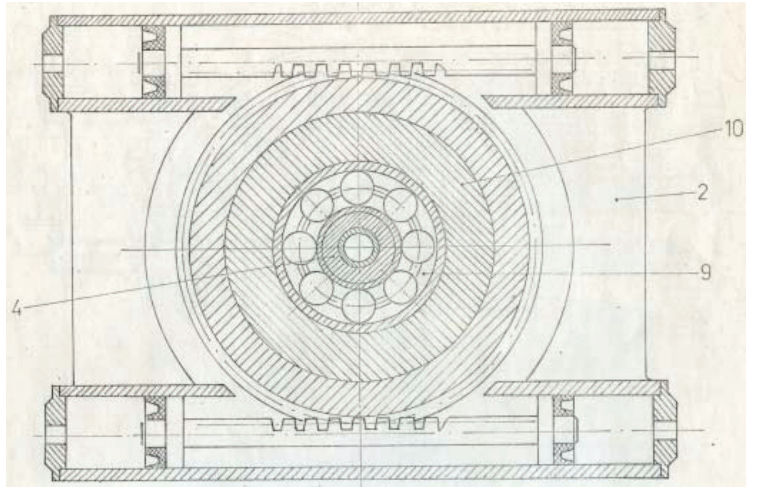

Fig. 5. Cross section through the crimping head presenting the oscillating hydraulic [24].

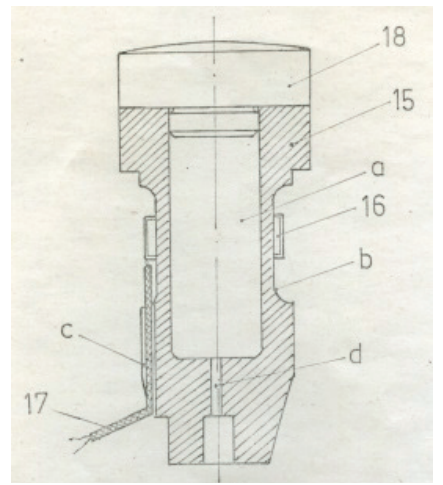

Fig. 6. Section through gripping jaw adapted for force measurement [24].

The second claim (see Figure 6): An automatic crimping machine as in claim 1 , characterized in that, in a second constructive variant, one of the gripping jaw (6) is replaced with another gripping jaw (C) which is constructed of a body (15), provided with a cylindrical bore (a) and a concentric throating (b), on which some strain marks (16) are attached, from which a conductor (17) which transmits the pressing information to the electronic control equipment, the body (15) being closed by a pressed cap (18) and provided with a hole (d) for eliminating the air.

The third claim (see Figure 7): an automatic crimping machine according to claim 1 , characterized in that the crimping tool (7) has a conical area (e) in which two 
parallel planar surfaces (f) and a semitoidal surface (g), the tool being provided with a cylindrical area $(\mathrm{h})$ in which a flat surface (i) is machined.
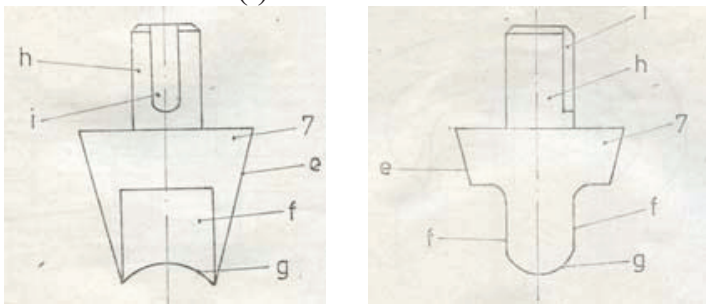

Fig. 7. Crimping tool [25].

The fourth claim (see Figure 3): an automatic crimping machine according to claim 1 , characterized in that, the positioning block (B) is constituted by a cylinder body (19) in which a piston (20) mounted in the middle of a tubular rod (21) having on its end a chuck collet (22) and a ruler on the other end with the limiter (23). Inside the tubular rod (21) there is moved a piston (24) mounted on a rod (25) carrying a conical element (26) which, together with the chuck collet (22), performs the gripping under the action of a fluid, which selected by a distributor (27), go through an orifice (j) into a cavity (k) in the cylinder (19), from where through an orifice (l) is introduced into a cavity (m) of the rod (21),producing first the pretension by first moving the piston (24) and then positioning by further displacement of the piston (20) by the discharge of the fluid from a cavity (n) by means of an orifice (o) associated with a hydraulic resistance (28), compared to the discharge of the fluid from a cavity (p) through an orifice (r) without hydraulic resistance.

It is important to note, for the sake of understanding the context, that the product obtained by using the machine in the patent is a hose assembled by nipple crimping (as shown in Figure 8).

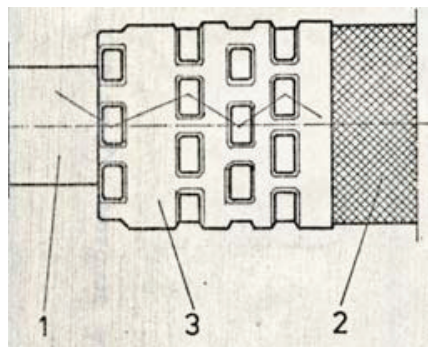

Fig. 8. Hose assembled by nipple crimping [26].

The analysis will be made from the perspective of applying the Axiomatic Design theory based on mapping concepts between the two fields. When analysing an existing system, we must determine the design matrix to see if the design violates the axiom 1 or not.

\subsection{Identification of functional requirements}

Analysis of the patent specification and claims as a whole reveals the following functional requirements:

$\mathrm{FR}_{1}$ - Functional requirement crimping;

$\mathrm{FR}_{2}$ - Functional requirement measurement;

$\mathrm{FR}_{3}$ - Functional requirement positioning.

\subsection{Identification of design parameters}

Analysis of patent claims reveals the following design parameters:

$\mathrm{DP}_{1}$ - Design parameter described in claim 1; assure functional requirements $\mathrm{FR}_{1}$;

$\mathrm{DP}_{2}$ - Design parameter described in claim 2; assure functional requirements $\mathrm{FR}_{2}$ (measurement);

$\mathrm{DP}_{3}$ - Design parameter described in claim 4, assure functional requirement $\mathrm{FR}_{3}$ (positioning);

$\mathrm{DP}_{4}$ - Design parameter described in claim 3;

According with Theorem 3, when there are more DPs then FRs the design is either a redundant design or a coupled design. When the design is redundant it may be possible to combine some of DPs that affect a given FR to form a "dimensionless" group [22].

The piece shown in Figure 8 and described in claim 3 is attached to each of the pieces 6 visible in Figures 3 and 4, thus providing the FR1 functional requirement. Thus, DP1 design parameter may combine with the DP4 design parameter to form a single parameter to meet the FR1 functional requirement. Thus, the number of functional requirements is equal to the number of design parameters (Ideal design according to Theorem 4).

\subsection{Identification of design equation}

According with Axiomatic Design when we analyse an existing design we must determine the design matrix to determine whether the design violate Axiom 1.Questions to be answered:

What kind of design does this matrix represent?

How the design should be modified to satisfy Axiom 1?

The equation of design, now, is what is shown in relation (5):

$$
\left[\begin{array}{l}
F R_{1} \\
F R_{2} \\
F R_{3}
\end{array}\right]=\left[\begin{array}{ccc}
A_{11} & 0 & 0 \\
A_{21} & A_{22} & 0 \\
0 & 0 & A_{33}
\end{array}\right] *\left[\begin{array}{c}
D P_{1} \\
D P_{2} \\
D P_{3}
\end{array}\right]
$$

Assuring the functional requirement FR2 (measurement) is made by adapting a piece 6 (see Figures 3 and 4) as shown in Figure 6 and described in claim 2. Under these conditions the independent functional requirements are assured but by a decoupled design matrix.

\subsection{New structure for claim construction}

In line with those presented in Table 1 on mapping concepts in axiomatic design with patent concepts, the following can be stated:

1. Claim 1 combines with claim 3 and forms a single independent claim;

2. Claim 2 remains an dependent claim;

3. Claim 4 becomes 3 and turns from an dependent claim to an independent claim.

Therefore, the initial claim structure consisting of an independent claim and three dependent claims should be replaced by a structure consisting of two independent 
claims and one dependent on all the legal consequences resulting therefrom.

\section{Conclusions}

The hypothesis made in chapter 4 according to which Axiomatic Design theory could be used to the construction of patent claims and to analyse the solutions claimed in existing patents appears to be confirmed.

The multitude of corollaries and theorems belonging to Axiomatic Design theory can be a powerful tool for scientifically solving a controversial issue in patenting: the claims.

Future work will be geared to different case studies to strengthen $\mathrm{AD}$ as a tool into patent field.

\section{References}

1. .Office of Policy and International Affairs: IP5, Available at: https://www.uspto.gov/patents-gettingstarted/international-protection/office-policy-andinternational-affairs-ip5

2. United States Patent and Trademark Office, Office of Policy and International Affairs: IP5, Available at: https://www.uspto.gov/patents-gettingstarted/international-protection/office-policy-andinternational-affairs-ip5

3. Patent Cooperation Treaty (PCT), Available at: http://www.wipo.int/export/sites/www/pct/en/texts/p df/pct.pdf

4. Regulations under the Patent Cooperation Treaty, Available at: http://www.wipo.int/export/sites/www/pct/en/texts/p df/pct_regs.pdf

5. Administrative Instructions Under The Patent Cooperation Treaty, Available at: http://www.wipo.int/export/sites/www/pct/en/texts/p df/ai.pdf

6. Korean Patent Act, Available at: http://www.kipo.go.kr/upload/en/download/PATEN T_ACT.pdf

7. Korean Enforcement decree of the patent act, Available

at: http://www.kipo.go.kr/upload/en/download/ENFOR CEMENT_DECREE_OF_THE_PATENT_ACT.pdf

8. The European Patent Convention and the Rules Available at: http://documents.epo.org/projects/babylon/eponet.ns f/0/F9FD0B02F9D1A6B4C1258003004DF610/\$Fil e/EPC_16th_edition_2016_en.pdf

9. Japan, Examination Guidelines for Patent and Utility Model, Available at: http://www.jpo.go.jp/tetuzuki_e/t_tokkyo_e/1312002_e.htm

10. Japan, Examination Handbook for Patent and Utility Model, Available at: http://www.jpo.go.jp/tetuzuki_e/t_tokkyo_e/handbo ok_sinsa_e.htm
11. Japan, Handbook for PCT International Search and Preliminary Examination in the Japan Patent Office, Available at: http://www.jpo.go.jp/tetuzuki_e/t_tokkyo_e/pct_han dbook_e.htm

12. Patent Law of the People's Republic of China Available http://english.sipo.gov.cn/laws/lawsregulations/2011 01/t20110119_566244.html

13. Rules for the Implementation of the Patent Law of the People's Republic of China, Available at: http://english.sipo.gov.cn/laws/lawsregulations/2014 03/t20140331_925757.html

14. Romanian Patent Law no. 64/1991 Available at: http://www.osim.ro/index3_files/laws/patents/Legea _nr64_1991_rep2014-en.pdf

15. Romanian implementing regulation to the Patent Law no. 64/1991, Available at: http://www.osim.ro/index3_files/laws/patents/imple mentingregmodif.pdf

16. Peter S. Menell, Matthew D. Powers, Steven C. Carlson, Patent Claim Construction: A Modern Synthesis and Structured Framework, Berkeley Technology Law Journal 25, 2, 710-829 (2010)

17. Donald M. Cameron, Claim Construction available at: http://www.jurisdiction.com/patweb04.pdf

18. Ha Kung Wong and John P. Dillon, Fitzpatrick, Patent Claim Construction, Fitzpatrick, Cella, Harper \& Scinto, with Intellectual Property \& Technology, Available http://www.fitzpatrickcella.com/wpcontent/uploads/Patent-Claim-ConstructionWong_Dillon.pdf

19. Christian E. Mammen, Patent claim construction as a form of legal interpretation, John Marshall Review of Intellectual Property Law 40 (2012), Available at: http://ssrn.com/abstract $=2012571$

20. Garrod Glossary of Judicial Claim Constructions in the Mechanical, Electro- Mechanical and Medical Devices Arts, Available at: http://www.pubpat.org/garrod-glossaries.htm

21. XLPAT's CLAIM MAPPER for Claim Chart Generation and Claim Mapping of Patents Available at: https://xlpatlabs.wordpress.com/tag/claim-chartgenerator/

22. Suh N.P., The Principles of Design, New York : Oxford University Press, 1990.ISBN 0-19-504345-6

23. Suh N.P., Complexity. Theory and Applications (Oxford University Press, NY, 2005)

24. P. Dusa, St. Budacea, C. Tofan, C. Alexoaie, G. Bran, Automatic crimping machine, Patent RO no. 101886

25. P. Dusa, St. Budacea, F. Oproiu, I. Chiscop, Crimping method, Patent RO no. 106447 